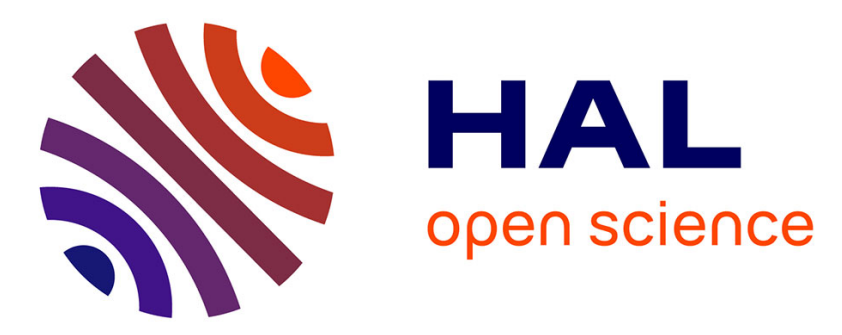

\title{
Investigation of the effect of temper rolling on the texture evolution and mechanical behavior of IF steels using multiscale simulation
}

Komi Soho, Xavier Lemoine, Farid Abed-Meraim, Hamid Zahrouni

\section{- To cite this version:}

Komi Soho, Xavier Lemoine, Farid Abed-Meraim, Hamid Zahrouni. Investigation of the effect of temper rolling on the texture evolution and mechanical behavior of IF steels using multiscale simulation. International Journal of Material Forming, 2017, 10 (1), pp.29-42. 10.1007/s12289-015-1257-4 . hal-02175178

\author{
HAL Id: hal-02175178 \\ https://hal.science/hal-02175178
}

Submitted on 5 Jul 2019

HAL is a multi-disciplinary open access archive for the deposit and dissemination of scientific research documents, whether they are published or not. The documents may come from teaching and research institutions in France or abroad, or from public or private research centers.
L'archive ouverte pluridisciplinaire $\mathbf{H A L}$, est destinée au dépôt et à la diffusion de documents scientifiques de niveau recherche, publiés ou non, émanant des établissements d'enseignement et de recherche français ou étrangers, des laboratoires publics ou privés. 


\title{
Investigation of the effect of temper rolling on the texture evolution and mechanical behavior of IF steels using multiscale simulation
}

\author{
Komi Soho $^{1}$ - Xavier Lemoine ${ }^{2,3}$ - Farid Abed-Meraim ${ }^{2} \cdot$ Hamid Zahrouni $^{1}$
}

\begin{abstract}
The main objective of this study is to simulate texture and deformation during the temper-rolling process. To this end, a rate-independent crystal plasticity model, based on the self-consistent scale-transition scheme, is adopted to predict texture evolution and deformation heterogeneity during temper-rolling process. For computational efficiency, a decoupled analysis is considered between the polycrystalline plasticity model and the finite element analysis for the temper rolling. The elasto-plastic finite element analysis is first carried out to determine the history of velocity gradient during the numerical simulation of temper rolling. The thus calculated velocity gradient history is subsequently applied to the polycrystalline plasticity model. By following some appropriately selected strain paths (i.e., streamlines) along the rolling process, one can predict the texture evolution of the material at the half thickness of the sheet metal as well as other parameters related to its microstructure. The numerical results obtained by the proposed strategy are compared with experimental data in the case of IF steels.
\end{abstract}

Komi Soho

komi.soho@univ-lorraine.fr

1 Laboratoire d'Étude des Microstructures et de Mécanique des Matériaux, LEM3, UMR CNRS 7239, Université de Lorraine, Ile du Saulcy, 57045 Metz, France

2 Laboratoire d'Étude des Microstructures et de Mécanique des Matériaux, LEM3, UMR CNRS 7239, Arts et Métiers ParisTech, 4 rue Augustin Fresnel, 57078 Metz Cedex 03, France

3 ArcelorMittal R\&D Global Maizières, Automotive Product, Voie Romaine, BP 30320, 57283 Maizières-Lès-Metz Cedex, France
Keywords Micromechanics · Crystal plasticity · Self-consistent scale transition · Finite elements . Elasto-plasticity $\cdot$ Sheet metal forming processes

\section{Introduction}

Sheet metal forming is a process commonly used to obtain mechanical parts in areas as diverse as automotive industry, packaging or equipment. This involves a very important property studied in industry, namely the material formability. Formability is the capacity in which a metal may be shaped by plastic deformation without cracks, failure, or any area where the deformation is localized. To prevent the occurrence of these phenomena during forming, it would be interesting to determine relationships between texture and microstructure, which evolve within the sheet metal during forming, and the resulting mechanical properties. This would also allow optimizing the microstructural characteristics of sheet metals in order to reach the best compromise between some desirable but often conflicting mechanical properties, such as high strength and good ductility.

The development of software tools has allowed the emergence of computer codes able to simulate the behavior of structures subjected to complex loadings. In this area, the finite element (FE) method became effective to accurately assess the response of a structure submitted to any loading case, with relatively low computation times. Traditional FE computer codes are now commonly used for the numerical simulation of forming processes. However, these software packages still have several limitations. These restrictions are mainly related to the built-in constitutive models, which are essentially phenomenological thus not accounting for the physical mechanisms of plasticity and the underlying microstructure evolution. These codes also have difficulty in predicting the 
texture induced plastic anisotropy, as pointed out by Poortmans et al. [1]. In order to predict the texture evolution and texture induced plastic anisotropy (see Gawad et al. [2], Van Houtte et al. [3, 4], Tóth and Molinari [5]) during the forming process, there were numerous attempts to use the crystal plasticity (CP) model along with FE analysis.

The crystal plasticity finite element (CPFE) method, launched by Peirce et al. [6], is nowadays extensively used to solve problems involving mechanical behavior of crystalline materials. This methodology combines single crystal plasticity, as constitutive description, and FE analysis, as numerical solver for the associated boundary-value problem. For a comprehensive review on these methods, see e.g. Roters et al. [7]. Most of the CPFE applications found in the literature are based on the numerical solution of the single crystal plasticity constitutive equations directly within the FE analysis (in most cases, with intragranular resolution, i.e. comprising several integration points and, usually, several elements per grain).

Another approach is to use a polycrystal plasticity model as constitutive behavior of the material in a FE calculation. This consists in introducing in each material point of a FE calculation a constitutive law based on polycrystalline plasticity. Applications of this technique in numerical simulations of forming processes have been shown in the works of Boudifa et al. [8], Zamiri and Pourboghrat [9, 10], Zhang et al. [11], Li et al. [12], Li et al. [13], Guan and Pourboghrat [14], Segurado et al. [15], and Mathur and Dawson [16]. However, this technique turns out to be very heavy and requires processing of large volume of data, which leads to very high computation times. To reduce the computation time, while maintaining the accuracy of the calculation, technical approaches have been proposed in the literature, which consist in decoupling the crystal plasticity modeling from the FE simulations.

One of the earlier approaches in the above-mentioned category is referred to as the stress-strain interpolation method. This technique may be classified between two classes of models, analytical yield locus functions and micro-macro models. In terms of accuracy, this method allows following the yield stresses predicted by the Taylor theory more closely than a global sixth-order series yield locus adjusted on stresses computed by the Taylor model for the initial texture. For a comprehensive presentation of this method, see Habraken and Duchêne [17].

Another decoupling technical approach, which is easier to implement, consists in linking the CP model with FE analysis by extracting a macroscopic velocity gradient history, obtained from a preliminary low-cost FE simulation, and feeding it to a polycrystalline model (see, e.g., Peirce et al. [18], Asaro and Needleman [19], Kalidindi and Anand [20], Jung et al. [21]).

With regard to sheet metal forming processes, different types of constitutive models are commonly used. These may be classified into two main classes, namely viscoplastic (rate- dependent) and elasto-plastic (rate-independent) models. Viscoplastic laws apply in particular to the case of hot metal forming, for which the elastic response may be neglected. These laws have been more frequently adopted in numerical simulation of forming processes for crystalline materials. As compared to elasto-plastic models, they are easier to implement because they circumvent the issue of non-uniqueness in the determination of active slip systems (see, e.g., Franciosi and Zaoui [22], Anand and Kothari [23], Busso and Cailletaud [24], Arul Kumar and Mahesh [25]). On the other hand, elasto-plastic models (see Marin and Dawson [26]) find their interest in the case of cold metal forming. They may be used for the quantification of springback or for evaluation of resulting residual stresses.

In the present paper, a decoupled analysis, involving the elasto-plastic CP model and the FE method, is carried out for temper rolling in order to improve the computational efficiency without sacrificing accuracy. Temper rolling, also known as skin-pass rolling, represents the final forming stage in the production chain of cold rolled steel, in order to produce metal sheets with high flatness and low surface roughness. It is mainly used to prevent the formation of Lüders bands to eliminate the sharp yield point and subsequent plateaus (Jafarlou et al. [27], Yoshida et al. [28], Roberts [29]).

The procedure adopted in the current work is summarized as follows. Firstly, an elasto-plastic FE analysis is conducted to determine the history of the velocity gradient during temper-rolling process. Then, the obtained velocity gradient history is provided to the polycrystalline model. By following some appropriately selected strain paths (i.e., streamlines) along the rolling process, one can predict the texture evolution of the material at the half thickness of the sheet metal as well as other parameters related to its microstructure. This work is part of a larger project aiming at the numerical simulation of the production chain of cold-rolled flat products. To this end, the current contribution may be seen as a prerequisite intended to validate some physical features relating to the microstructure, such as crystallographic texture, morphological texture, stored energy, etc.

\section{Constitutive modeling}

\section{Single crystal constitutive model}

The micromechanical modeling used in this study is based on the work of Lipinski and Berveiller [30], dealing with elastoplasticity of metals at large strains.

First of all, it is necessary to specify the assumptions on which the material behavior at the grain scale is based. The single crystal constitutive law is assumed to be elasto-plastic, with plastic deformation only due to crystallographic slip; the other modes of inelastic deformation, such as twinning or 

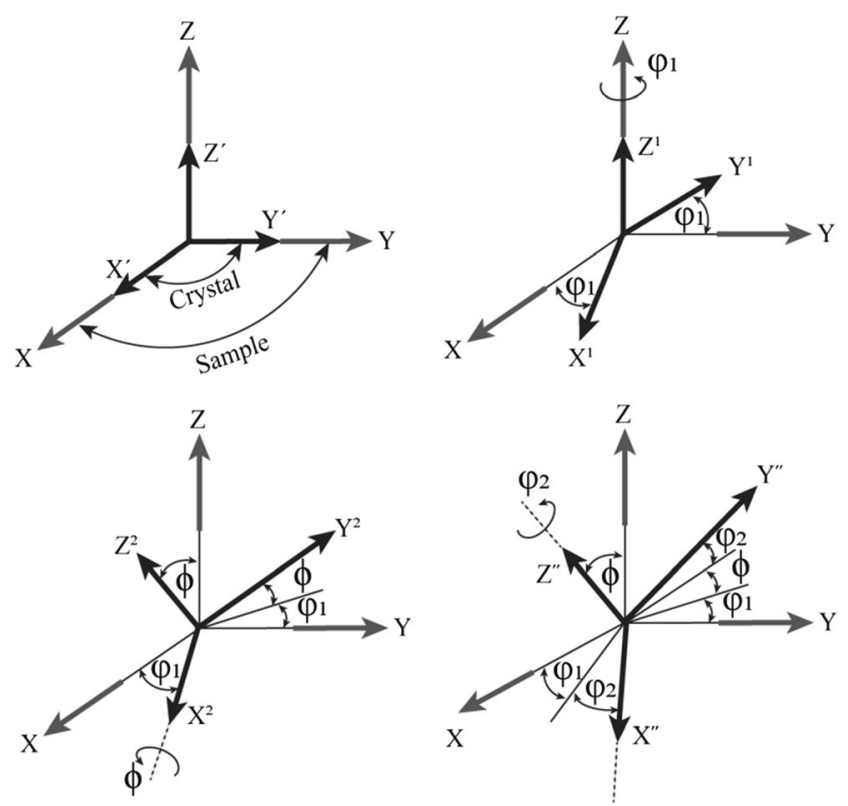

Fig. 1 Schematic representation defining the three Euler angles $\varphi_{1}, \phi$, $\varphi_{2}$ according to Bunge's notation

phase transformation, are not taken into account in the scope of this study. The local incremental elasto-plastic constitutive law is defined by means of the tangent modulus $\mathbf{l}$, relating the nominal stress rate $\dot{\mathbf{n}}$ to the velocity gradient $\mathbf{g}$

$\dot{\mathbf{n}}=\mathbf{l}: \mathbf{g}$.

The above velocity gradient is the sum of the total strain rate $\mathbf{d}$ and total rotation rate $\mathbf{w}$, which are respectively the symmetric and anti-symmetric part of the velocity gradient

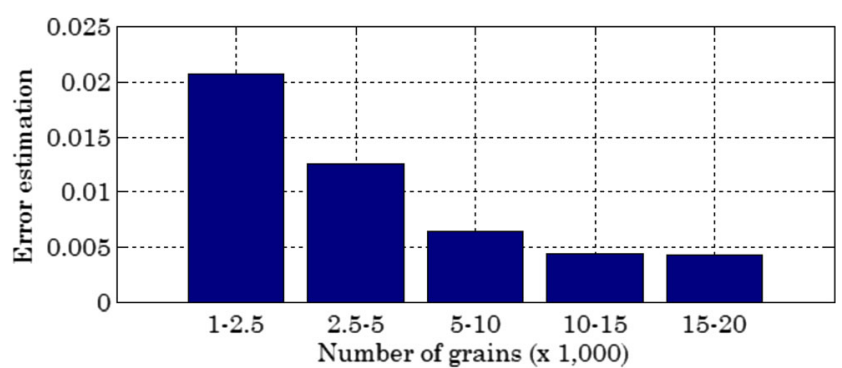

Fig. 2 Error estimation of orientation distribution functions according to the number of grains

g. The latter two parts can be further divided into an elastic part, with a superscript $\mathrm{e}$, and a plastic part with superscript $\mathrm{p}$. The plastic parts (plastic strain rate and plastic spin) are related to the slip rates $\dot{\gamma}^{\mathrm{g}}$ by

$$
\begin{aligned}
& \mathbf{d}^{\mathrm{p}}=\mathbf{d}-\mathbf{d}^{\mathrm{e}}=\sum_{\mathbf{g}} \mathbf{R}^{\mathrm{g}} \dot{\gamma}^{\mathrm{g}}, \\
& \mathbf{w}^{\mathrm{p}}=\mathbf{w}-\mathbf{w}^{\mathrm{e}}=\sum_{\mathbf{g}} \mathbf{S}^{\mathrm{g}} \dot{\gamma}^{\mathrm{g}},
\end{aligned}
$$

where $\mathbf{R}^{\mathrm{g}}$ and $\mathbf{S}^{\mathrm{g}}$ denote, respectively, the well-known symmetric and anti-symmetric part of the Schmid tensor, associated with a given slip system $g$, while $\mathbf{d}^{\mathrm{e}}$ and $\mathbf{w}^{\mathrm{e}}$ designate the elastic strain rate and lattice spin, respectively. A rateindependent regularization law [31] is adopted for the determination of the slip rates

$\dot{\gamma}^{g}=k^{g} \dot{\tau}^{g}$

where $H^{g g}$ is the self-hardening term, 'tanh' denotes the hyperbolic tangent function, $\tau^{g}$ and $\tau_{c}^{g}$ are the resolved shear stress and critical shear stress, respectively, associated with slip system $\mathrm{g}$, and $k_{0}, k_{1}, k_{2}, \tau_{r e f}$, and $\dot{\tau}_{r e f}$ are numerical parameters associated with the regularization function (see [31]). The expression of the elastoplastic tangent modulus is then derived as follows (see [32]):

$l_{i j k l}=\left[C_{i j k l}-\frac{1}{2}\left(\sigma_{i k} \delta_{j l}-\sigma_{i l} \delta_{j k}\right)-\frac{1}{2}\left(\delta_{i k} \sigma_{j l}+\delta_{i l} \sigma_{j k}\right)\right]-\left[\sum_{g, h}\left(C_{i j m n} R_{m n}^{g}+S_{i m}^{g} \sigma_{m j}-\sigma_{i m} S_{m j}^{g}\right) P^{g h} R_{p q}^{\prime h}\left(C_{p q k l}-\sigma_{p q} \delta_{k l}\right)\right]$,

where $\delta_{j l}$ is the Kronecker delta, $R_{p q}^{h}=k^{h} R_{p q}^{h}$, in which the regularization function $k^{h}$ is given by Eq. (4), and $P^{g h}=\left(\delta^{h g}+\right.$ $\left.k^{h} \mathbf{R}^{h}: \mathbf{C}: \mathbf{R}^{g}\right)^{-1}$. Note that in the latter expression, $\delta^{g h}$ are the components of the identity matrix, whose size is the current 
Fig. 3 Section of orientation distribution functions at $\varphi_{2}=45^{\circ}$ for real material and pseudomaterial, with 5000 grains, in mid-thickness of the sheet metal: (a) experiment; (b) pseudomaterial

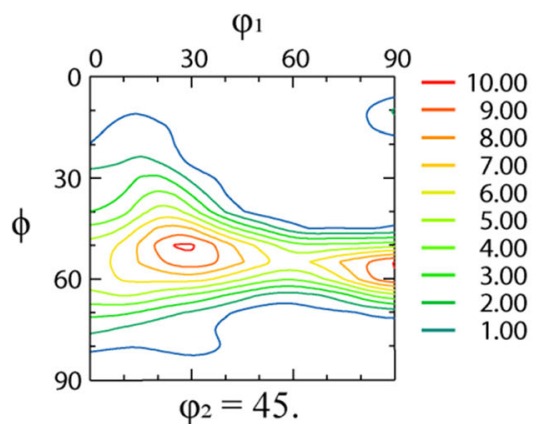

(a)

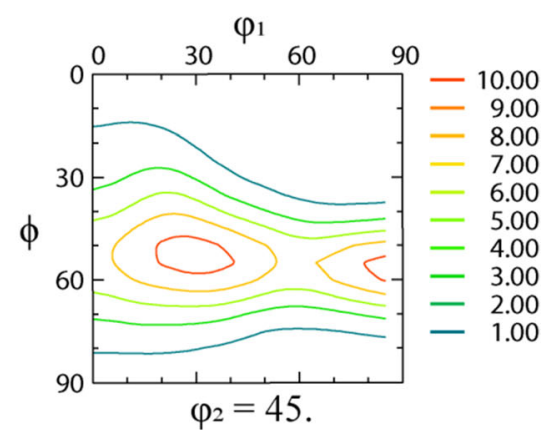

(b) number of active slip systems; while $\mathbf{C}$ is the fourth-order elasticity tensor and $\boldsymbol{\sigma}$ the Cauchy stress tensor.

The evolution law for the critical shear stress, in terms of slip rates, can be expressed as follows (see [32]):

$\dot{\tau}_{c}^{g}=\sum_{h=1}^{n s l i p} H^{g h} \dot{\gamma}^{h}$

with

$$
H^{g h}=\frac{\alpha \mu}{2 \sqrt{\sum_{k=1}^{n s l i p} a^{g k} \rho^{k}}} a^{g h}\left(\frac{1}{L^{h}}-2 y_{c} \rho^{h}\right),
$$

where $\alpha$ is a constant related to the stability of dislocation configurations, $\mu$ is the shear modulus, $a^{g h}$ is the anisotropy interaction matrix, nslip is the number of slip systems, $\rho^{h}$ is the mean dislocation density for slip system $\mathrm{h}$, $y_{c}$ is the critical annihilation distance of dislocations, and $L^{g}$ is the mean free path of dislocations on the slip system $\mathrm{g}$, which is given by

$\frac{1}{L^{g}}=\frac{1}{D_{\text {moy }}}+\frac{\sqrt{\sum_{h=1, h \neq g}^{n s l i p} \rho^{h}}}{g_{0}}$,

where $D_{\text {moy }}$ represents the average grain size and $g_{0}$ corresponds to the parameter related to dislocation storage.

\section{Self-consistent scale transition and polycrystalline behavior}

To derive the overall polycrystalline behavior, from knowledge of the behavior of individual grains, a self-consistent scheme is used. Only the main lines of this classical approach are presented here, all of the averaging scheme details are developed in [33] as well as in [34].

The macroscopic behavior law, linking the macroscopic fields - nominal stress rate $\dot{\mathbf{N}}$ and velocity gradient $\mathbf{G}$ - by means of the yet-unknown macroscopic tangent modulus $\mathbf{L}$, has the same incremental form as that of the single crystal (Eq. (1))

$$
\dot{\mathbf{N}}=\mathbf{L}: \mathbf{G},
$$

where the macroscopic fields are defined as the volume averages of their microscopic counterparts

$$
\left\{\begin{array}{l}
\mathbf{G}=\frac{1}{\mathrm{v}} \int_{\mathrm{v}} \mathbf{g}(\mathrm{x}) \mathrm{dv}=\overline{\mathbf{g}(\mathrm{x})}, \\
\dot{\mathbf{N}}=\frac{1}{\mathrm{v}} \int_{\mathrm{v}} \dot{\mathbf{n}}(\mathrm{x}) \mathrm{dv}=\overline{\dot{\mathbf{n}}(\mathrm{x})} .
\end{array}\right.
$$

Then, the following fourth-order concentration tensor needs to be introduced to obtain a systematic expression of the macroscopic tangent modulus:

$\mathbf{g}(\mathrm{x})=\mathbf{A}(\mathrm{x}): \mathbf{G}$.
Fig. 4 Section of orientation distribution functions at $\varphi_{2}=45^{\circ}$ for real material and pseudomaterial, with 5000 grains, in subsurface of the sheet metal: (a) experiment; (b) pseudo-material

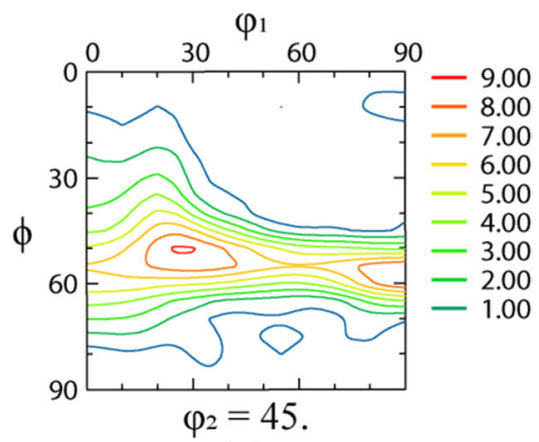

(a)

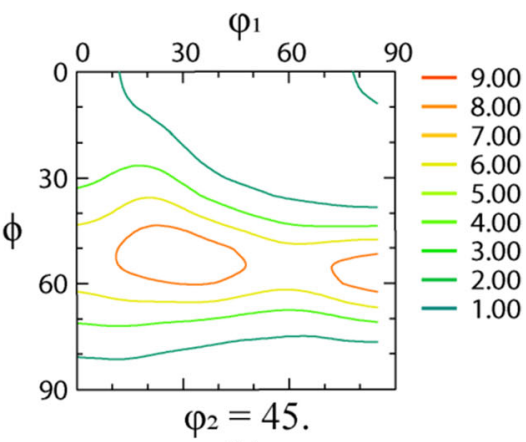

(b) 
Under these conditions, it is easy to show that the macroscopic tangent modulus is given by

$\mathbf{L}=\frac{1}{\mathrm{~V}} \int_{\mathrm{v}} \mathbf{l}(\mathrm{x}): \mathbf{A}(\mathrm{x}) \mathrm{dv}=\overline{\mathbf{I}(\mathrm{x}): \mathbf{A}(\mathrm{x})}$.

At this stage, it is commonly assumed that for each individual grain, the behavior and mechanical fields are homogeneous. For a given grain I of volume $\mathrm{V}^{\mathrm{I}}$, an indicator function $\theta^{\mathrm{I}}$ is defined by

$\left\{\begin{array}{l}\theta^{\mathrm{I}}(\mathrm{x})=1 \text { if } \mathrm{x} \in \mathrm{V}^{\mathrm{I}} \\ \theta^{\mathrm{I}}(\mathrm{x})=0 \text { if } \mathrm{x} \notin \mathrm{V}^{\mathrm{I}}\end{array}\right.$

leading to

$$
\left\{\begin{array}{l}
\mathbf{g}(\mathrm{x})=\sum_{\mathrm{I}=1}^{\mathrm{Ng}} \mathbf{g}^{\mathrm{I}} \theta^{\mathrm{I}}(\mathrm{x}) \\
\mathbf{I}(\mathrm{x})=\sum_{\mathrm{I}=1}^{\mathrm{Ng}} \mathrm{I}^{\mathrm{I}} \theta^{\mathrm{I}}(\mathrm{x})
\end{array}\right.
$$

where $\mathbf{g}^{\mathrm{I}}$ and $\mathbf{I}^{\mathrm{I}}$ are the volume average for grain I of the velocity gradient and the tangent modulus, respectively, and $\mathrm{Ng}$ is the number of grains within the polycrystalline aggregate.

By using Green's tensor techniques in order to transform the problem into an integral equation (the interested reader may refer to [30, 31, 34, 35] for the complete developments), it can be demonstrated, after some elaborate derivations, that the concentration tensor $\mathbf{A}^{\mathrm{I}}$ related to grain I is given by

$\mathbf{A}^{\mathrm{I}}=\left(\mathbf{I}-\mathbf{T}^{\mathrm{II}}:\left(\mathbf{I}^{\mathrm{I}}-\mathbf{L}\right)\right)^{-1}:{\overline{\left(\mathbf{I}-\mathbf{T}^{\mathrm{II}}:\left(\mathbf{I}^{\mathrm{I}}-\mathbf{L}\right)\right)^{-1}}}^{-1}$

where $\mathbf{I}$ is the fourth-order identity tensor and $\mathbf{T}^{\mathrm{II}}$ is the interaction tensor for grain I, which is related to Eshelby's tensor [36] for an ellipsoidal inhomogeneity. Explicit expressions for tensor $\mathbf{T}^{\mathrm{II}}$ can only be found for isotropic media; for general anisotropy, such as in the proposed model, an integral over the ellipsoid is obtained using Fourier's transforms [35], and its numerical evaluation is achieved by means of GaussLegendre quadrature. For a polycrystalline aggregate comprising $\mathrm{Ng}$ grains with a respective volume fraction $\mathrm{f}^{\mathrm{I}}$, the one-site self-consistent expression corresponding to the self-consistent scheme in the sense of Hill [37] can be finally obtained as

$\mathbf{L}=\sum_{\mathrm{I}=1}^{\mathrm{Ng}} \mathrm{f}^{\mathrm{I}} \mathbf{l}^{\mathrm{I}}: \mathbf{A}^{\mathrm{I}}$.

\section{Morphological and crystallographic evolution}

It is important to take into account morphological and crystallographic changes for each grain during loading. The change in crystallographic orientation is due to the lattice $\operatorname{spin} \mathbf{w}^{\mathrm{e}}$ (see, e.g., [38]). The relationships between the rates of Euler's
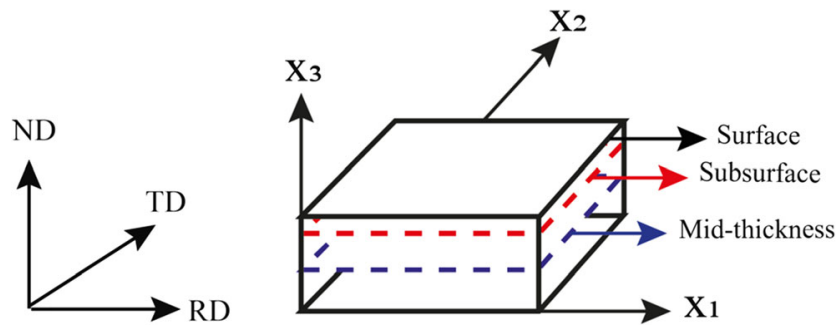

Fig. 5 Textural investigations in the plane (RD, ND) at different depths along the thickness direction

angles and lattice spin $\mathbf{w}^{\mathrm{e}}$ are

$$
\left\{\begin{array}{l}
\dot{\varphi}_{1}=-\mathrm{w}_{12}^{e}+\frac{\cos \phi}{\sin \phi}\left(w_{13}^{e} \cos \varphi_{1}+w_{23}^{e} \sin \varphi_{1}\right), \\
\dot{\phi}=-w_{23}^{e} \cos \varphi_{1}+w_{13}^{e} \sin \varphi_{1}, \\
\dot{\varphi}_{2}=-\frac{1}{\sin \phi}\left(w_{13}^{e} \cos \varphi_{1}+w_{23}^{e} \sin \varphi_{1}\right),
\end{array}\right.
$$

where $\varphi_{1}, \phi, \varphi_{2}$ are Euler's angles of a single crystal defining crystallographic orientation according to Bunge's notation [39, 40]. A schematic representation defining these three Euler angles is also given in Fig. 1. For the grain morphology, the morphological orientation evolves with the total rotation rate as

$$
\left\{\begin{array}{l}
\dot{\phi}_{1}^{\prime}=-\mathrm{w}_{12}+\frac{\cos \varphi^{\prime}}{\sin \varphi^{\prime}}\left(w_{13} \cos \phi_{1}^{\prime}+w_{23} \sin \phi_{1}^{\prime}\right) \\
\dot{\boldsymbol{\omega}}^{\prime}=-w_{23} \cos \phi_{1}^{\prime}+w_{13} \sin \phi_{1}^{\prime} \\
\dot{\phi}_{2}^{\prime}=-\frac{1}{\sin \varphi^{\prime}}\left(w_{13} \cos \phi_{1}^{\prime}+w_{23} \sin \phi_{1}^{\prime}\right)
\end{array}\right.
$$

where $\varphi_{1}^{\prime}, \phi^{\prime}, \varphi_{2}^{\prime}$ are Euler's angles of a single crystal defining morphological orientation according to Bunge's notation. These angles define the orientation of the principal coordinate system of the ellipsoid representing the grain relative to the coordinate system (RD, TD, ND) of the sample. The evolution

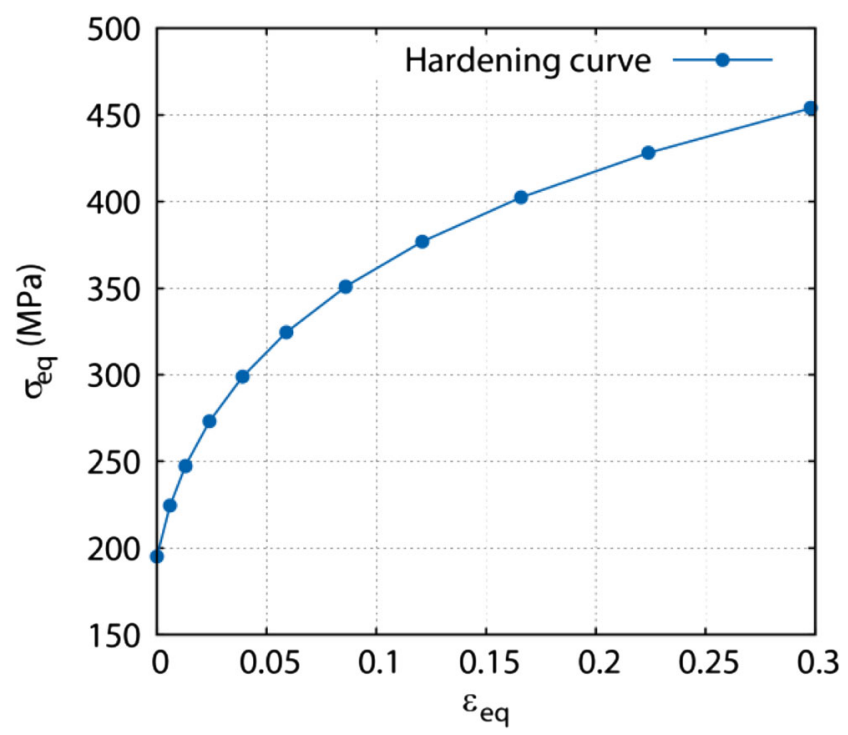

Fig. 6 The hardening curve of the simulated steel 
Table 1 Parameters of the temper-rolling process

\begin{tabular}{ll}
\hline Input thickness & $0.256 \mathrm{~mm}$ \\
\hline Reduction & $1.3 \%$ \\
& $4.8 \%$ \\
& $10.2 \%$ \\
& $14.2 \%$ \\
& $20 \mathrm{~mm}$ \\
Width of the sheet metal & $80 \mathrm{~mm}$ \\
Length of the sheet metal & $1 \mathrm{~m} / \mathrm{s}$ \\
Rolling velocity & $70 \mathrm{~mm}$ \\
Roll diameter & Coulomb: $\tau=0.03 \times \sigma_{\mathrm{n}}$ \\
Friction law & Young's modulus $=208 \mathrm{GPa}$ \\
Elasticity constants & Poisson's ratio $=0.3$ \\
\end{tabular}

of the shape of the grains taken as ellipsoids is due to the total deformation rate as

$$
\left\{\begin{array}{l}
\dot{\mathrm{a}}=\mathrm{ag}_{11}^{\mathrm{ell}}, \\
\dot{\mathrm{b}}=\mathrm{bg}_{22}^{\mathrm{ell}}, \\
\dot{\mathrm{c}}=\mathrm{cg}_{33}^{\mathrm{ell}},
\end{array}\right.
$$

where $\mathrm{a}, \mathrm{b}$ and $\mathrm{c}$ are the half-axes of the ellipsoid representing the shape of the grain, while $\mathbf{g}^{\text {ell }}$ is the projection of the velocity gradient onto the morphological frame.

\section{Material parameters identified for the model}

Four parameters need to be identified using mechanical tests:

- $\tau_{0}$ representing the initial critical shear stress.

- $\mathrm{g}_{0}$ the parameter related to the mean free path of dislocations.

- $y_{c}$ the critical annihilation distance of dislocations.

- $\mathrm{D}_{\text {moy }}$ the average grain size.

One should also provide the model with the initial dislocation density (identical for all slip systems), the initial crystallographic texture (or Euler angle triplet for all single crystals), as well as the classical values of the norm of the Burgers vector and the shear modulus (isotropic elastic behavior).

\section{Selection of the number of grains representative of the initial texture}

For the initial crystallographic texture, we constructed a pseudo-material starting from the work of François et al.
Fig. 7 Evolution of the velocity gradient, at different reductions, along the rolling direction, in midthickness of the sheet metal: (a) $1.3 \%$ of reduction; (b) $4.8 \%$ of reduction; (c) $10.2 \%$ of reduction; (d) $14.2 \%$ of reduction

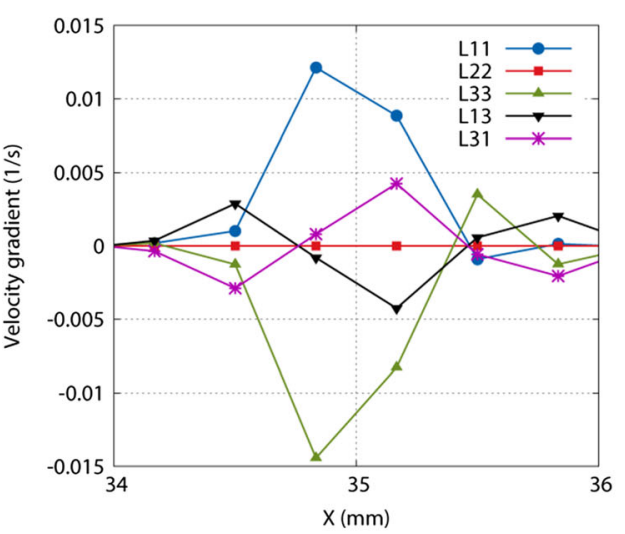

(a)

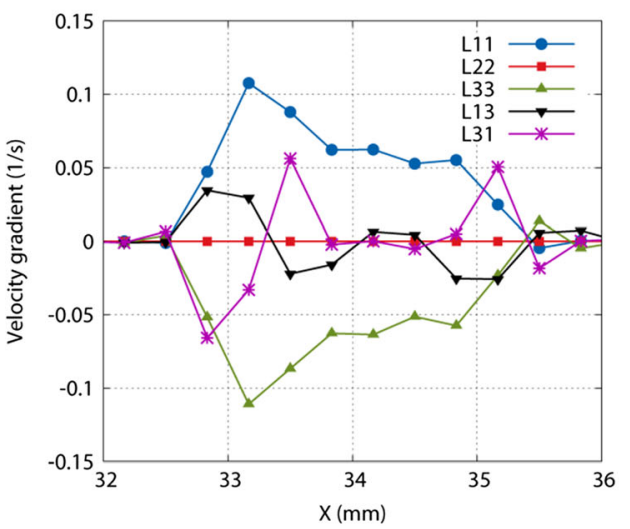

(c)

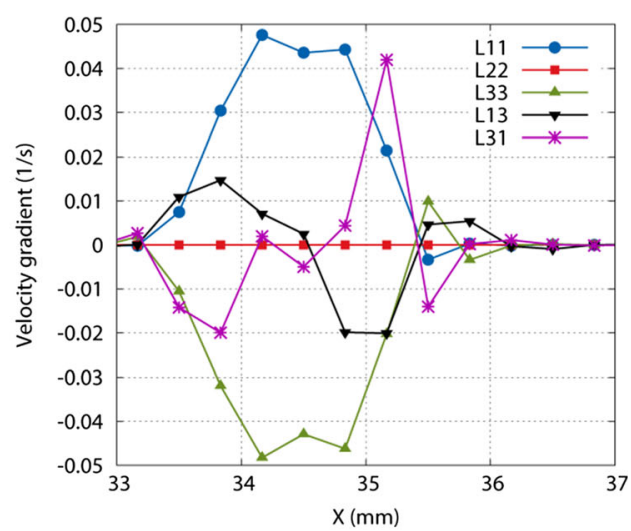

(b)

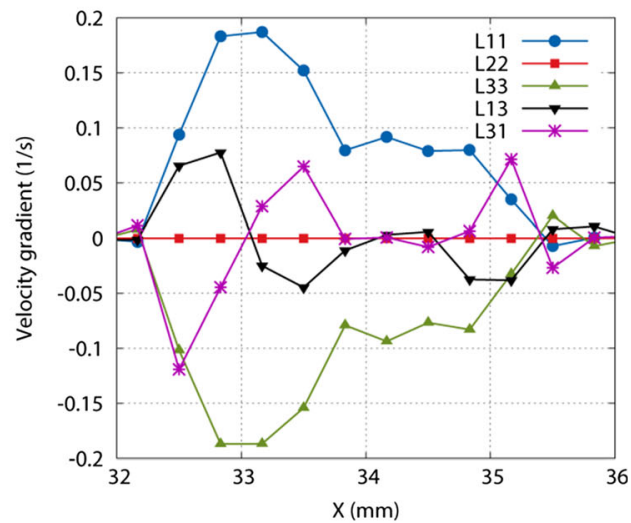

(d) 
[41]. In the related reference, it is explained how to make a statistically representative selection of orientations present in the actual material from its orientation distribution function (ODF). We define the orientation repartition functions (ORF) of $\varphi_{1}, \phi, \varphi_{2}$ by relations (20), (21), (22).

$\operatorname{ORF}\left(\varphi_{1}\right)=\frac{\int_{0}^{\varphi_{1}} M D F_{\varphi_{1}}\left(\varphi_{1}\right) d \varphi_{1}}{\int_{0}^{\varphi_{1_{\max }}} M D F_{\varphi_{1}}\left(\varphi_{1}\right) d \varphi_{1}}$,

$\operatorname{ORF}\left(\phi \mid \varphi_{10}\right)=\frac{\int_{0}^{\phi} M D F_{\varphi_{1} \phi}\left(\varphi_{10}, \phi\right) \sin \phi d \phi}{M D F_{\varphi_{1}}\left(\varphi_{10}\right)}$

$\operatorname{ORF}\left(\varphi_{2} \mid \varphi_{10}, \phi_{0}\right)=\frac{\int_{0}^{\varphi_{2}} \operatorname{ODF}\left(\varphi_{10}, \phi_{0}, \varphi_{2}\right) d \varphi_{2}}{M D F_{\varphi_{1} \phi}\left(\varphi_{10}, \phi_{0}\right)}$

with $\operatorname{MDF}$ of $\varphi_{1}$ the margin density function of $\varphi_{1}$ defined by relation (23), and margin density function of the couple $\left(\varphi_{1}, \phi\right)$ defined by relation (24).

$M D F_{\varphi_{1}}\left(\varphi_{1}\right)=\int_{0}^{\phi_{\max }} M D F_{\varphi_{1} \phi}\left(\varphi_{1}, \phi\right) \sin \phi d \phi$,
$M D F_{\varphi_{1} \phi}\left(\varphi_{1}, \phi\right)=\int_{0}^{\varphi_{2 \max }} \operatorname{ODF}\left(\varphi_{1}, \phi, \varphi_{2}\right) d \varphi_{2}$.

In Eqs. (20)-(24), $\varphi_{10}$ is the value of $\varphi_{1}$ derived from (20), $\phi_{0}$ is the value of $\phi$ derived from (21), while the other constant parameters are given by $\varphi_{1_{\max }}=2 \pi, \phi_{\max }=\pi, \varphi_{2_{\max }}=2 \pi$ (see [41] for more details).

All three orientation repartition functions, thus defined, allow us to transform the ODF into uniform distributions over $[0,1]^{*}[0,1]^{*}[0,1]$. These functions are monotonically increasing over the Euler space, and are therefore reversible. At any value of triplet $(\mathrm{u}, \mathrm{v}, \mathrm{w})$ in the range $[0,1]$, we can match a triplet of Euler angles defining a crystallite.

To determine the number of orientations necessary to conveniently represent the initial texture of the material, we can use the following estimated error between two different pseudo-materials:

$E-E\left(O D F_{1}, O D F_{2}\right)=\int_{\Omega} \frac{\left|O D F_{1}(\Omega)-O D F_{2}(\Omega)\right|}{O D F_{1}(\Omega)} d \Omega$,

where $E$ - $E$ stands for the error estimation, and $\Omega=\left(\varphi_{1}, \phi, \varphi_{2}\right)$ denotes the triplet of Euler angles.

The material considered in this study is interstitial free steel, commonly designated as IF steel. This material is
Fig. 8 Evolution of the strain, at different reductions, along the rolling direction, in mid-thickness of the sheet metal: (a) $1.3 \%$ of reduction; (b) $4.8 \%$ of reduction; (c) $10.2 \%$ of reduction; (d) $14.2 \%$ of reduction

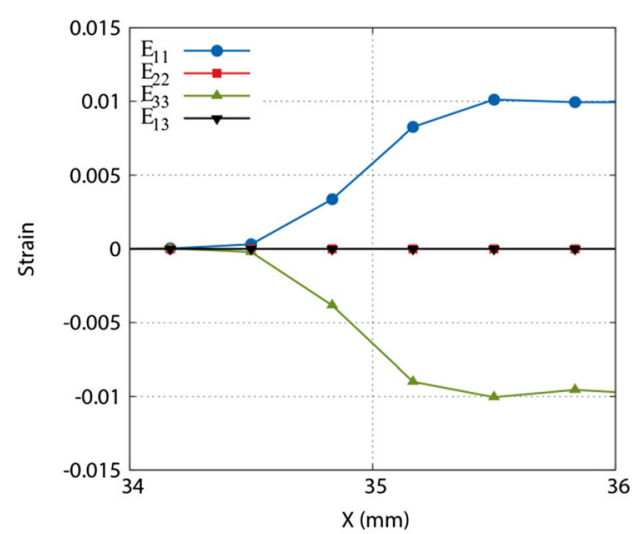

(a)

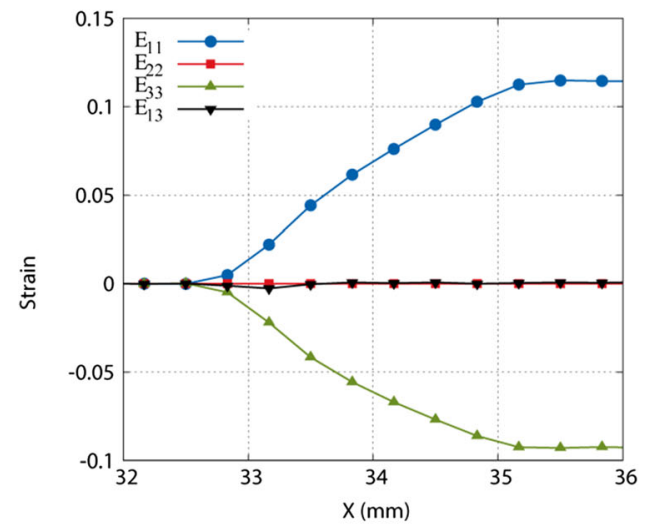

(c)

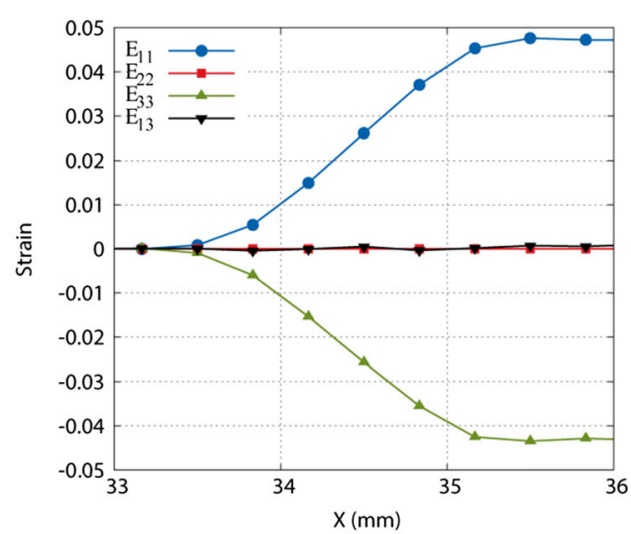

(b)

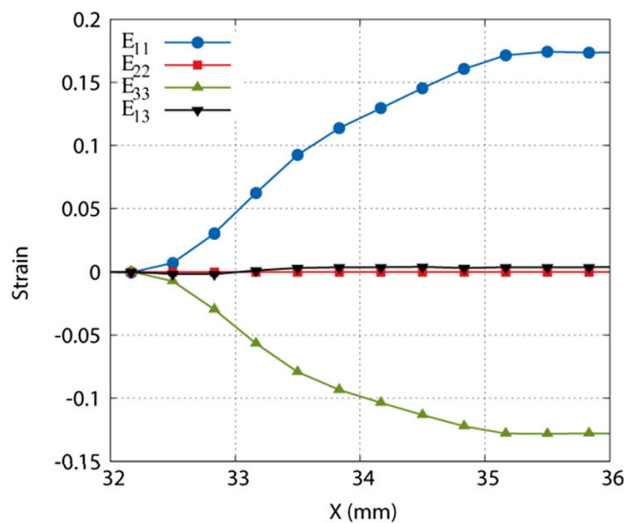

(d) 
Table 2 Identified material parameters for IF steel

\begin{tabular}{llllll}
\hline Parameters & $\tau_{0}[\mathrm{MPa}]$ & $\mathrm{g}_{0}$ & $\mathrm{y}_{\mathrm{c}}[\mathrm{nm}]$ & $\mathrm{D}_{\text {moy }}[$ microns $]$ & Grains \\
\hline Value & 93.33 & 100 & 3.25 & 20 & 5,000
\end{tabular}

annealed, and its thickness is $0.256 \mathrm{~mm}$. We can observe from Fig. 2 a decrease in the error according to the increase in the number of grains. Figure 2 also suggests that the error is stabilized beyond a representative selection of 10,000 grains. To reduce the computation time in the self-consistent model, 5000 crystallographic orientations will be used to represent the initial texture of the material.

From 5000 crystallographic orientations, statistically selected by the previously described method, we calculate the ODF on regular grid in the reduced Euler space. For the ODF computation, we used the open source software Mtex [42] based on Matlab. The following parameters have been used to calculate the ODF in Mtex software (kernel ('de la Vallee Poussin', 'halfwidth', $8 *$ degree); 'resolution', $5 *$ degree).

In Figs. 3 and 4, we represent a section of ODF at $\varphi_{2}=45^{\circ}$, as obtained from both experiment and the pseudo-material, and associated respectively with the midthickness and subsurface (see Fig. 5) of the sheet metal. Qualitatively, the ODF level lines of the pseudo-material are in good agreement with those of real material.

\section{Decoupled algorithm between the polycrystalline model and the finite element code LAM3}

The main advantage of the fully coupled analysis, based on the FE method combined with a CP model, lies in the prediction of texture evolution during metal forming processes and the more realistic representation of the crystalline nature of metals in the deformation behavior. Nevertheless, because the analysis scheme requires very large computation times, it is then necessary to search for an appropriate compromise between the computation time and the accuracy of the simulation results.

In this regard, the decoupled analysis is used for texture evolution prediction during the temper-rolling process. The main steps in this decoupled analysis are given in what follows:

Step 1 . Extract the velocity gradient history in the neighborhood of a material point of interest with a preliminary finite element calculation using a simple phenomenological plasticity model.

Step 2. Use this velocity gradient history in a separate subsequent simulation, using an advanced selfconsistent polycrystalline model, outside the finite element environment.

The advantage of this strategy is to uncouple the FE method and the polycrystalline model thus reducing the number of variables involved in calculations. The downside is that the deformation history used is approximate, which is probably less accurate than the one that would have been obtained by a full calculation using the polycrystalline model.

In what follows, we will denote by 'FEC path' the loading path that is extracted from the preliminary phenomenologicallybased FE calculation.

\section{Simulation using the FE code LAM3}

For step 1, the simulation of temper rolling is performed using the implicit FE code LAM3. LAM3, a software
Fig. 9 Evolution of orientation distribution functions, in midthickness of the sheet metal, for the alpha fiber during deformation: (a) real material; (b) pseudo-material with 5000 grains

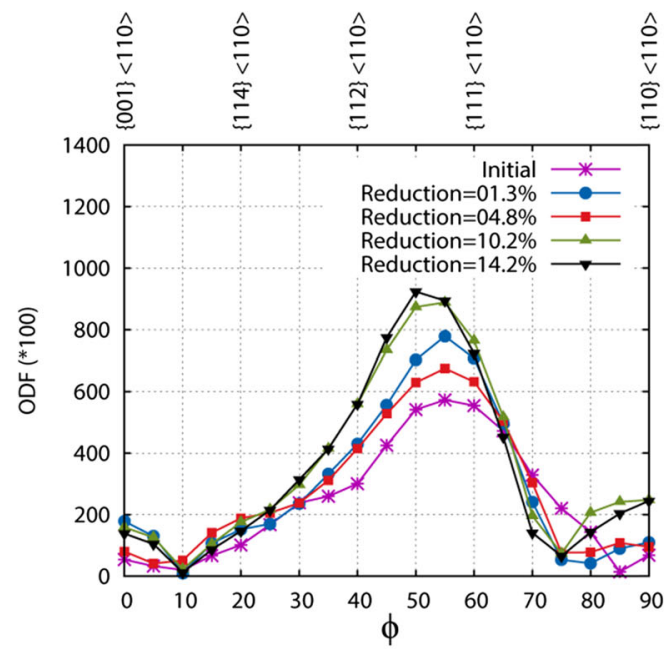

(a)

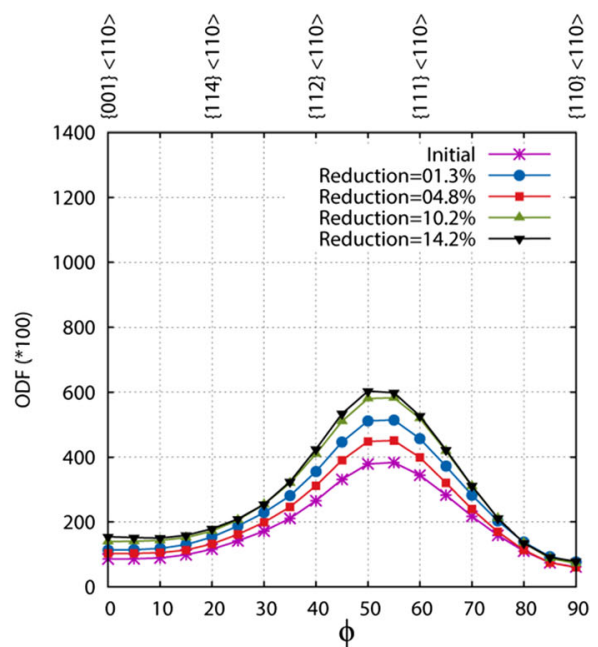

(b) 
Fig. 10 Evolution of orientation distribution functions, in midthickness of the sheet metal, for the gamma fiber during deformation: (a) real material; (b) pseudo-material with 5000 grains

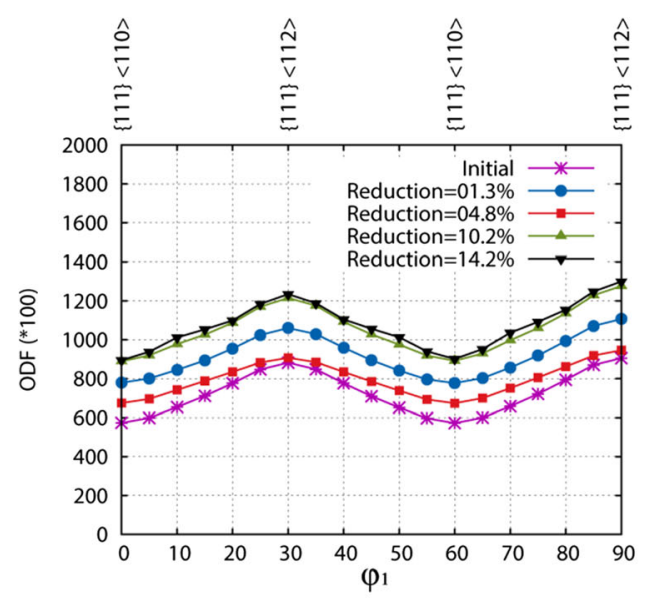

(a)

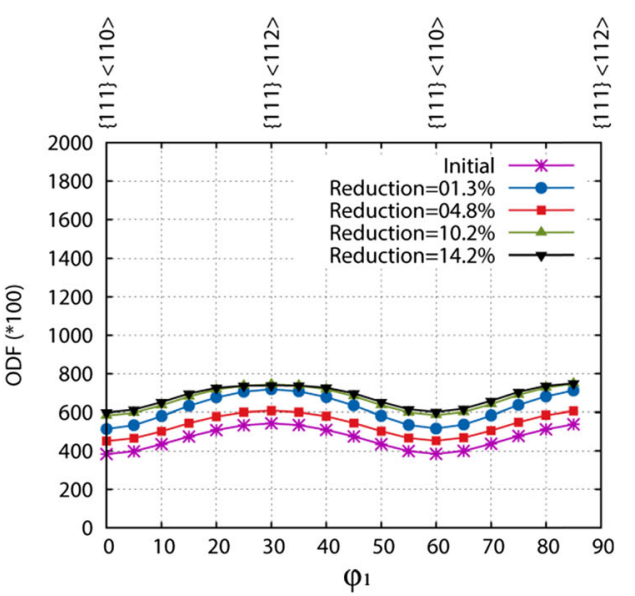

(b) package jointly developed by a consortium composed of Cemef, Transvalor, Arcelor Research and Alcan, solves the strip elasto-plastic strain by a 3D implicit FE procedure, and the roll stack elastic deformation by semianalytic models. LAM3 adopts an updated Lagrangian formulation with stationary and non-stationary versions (see, e.g., [43-46] for more details). The process consists in rolling a thin sheet metal, with a rolling velocity of the order of $1000 \mathrm{~mm} / \mathrm{s}$. The latter refers to the rolling speed or entraining velocity, which is closely related to the rate of rotation of the tools. This information is required for the simulation of rolling using LAM3, as it influences the way the sheet is caught in the grip through friction. A hardening law, whose representative curve is provided point by point, is used to model the material behavior (see Fig. 6). For the FE simulation, we used isotropic hardening along with a von Mises yield criterion. The input section has a width of $20 \mathrm{~mm}$, thickness of $0.256 \mathrm{~mm}$, and the length of the sheet metal is $80 \mathrm{~mm}$. Different reduction values were applied to the exit thickness, namely $1.3,4.8,10.2$, and $14.2 \%$. The diameter of the work roll is $70 \mathrm{~mm}$. All of the geometric and material parameters are summarized in Table 1. The roll of temper rolling is assumed to be rigid. Note that the dimensions quoted above are obviously not consistent with industrial application, but are motivated by comparisons with laboratory experiments provided by ArcelorMittal Research Division. The sheet metal is discretized with a mesh adapted to rolling process simulation, which uses refinement in the work area. For discretization, we used eightnode linear hexahedral elements with reduced integration (i.e., a single integration point in the center of the element). In this mesh, the number of nodes is equal to 1420 nodes, and the number of elements is equal to 840 , leading to a total number of degrees of freedom of 4260 DOF. For modeling, two planes of symmetry in the $y$ and $\mathrm{z}$ directions are used to reduce the computation domain.
For the subsequent analysis, the evolution of the velocity gradient and the total strain are recorded at certain current lines in the sheet thickness.

Figure 7 shows the evolution of the velocity gradient, at different reductions, along the rolling direction. Among nine velocity gradient components, it is found that only four, namely $L_{11}, L_{33}, L_{13}$, and $L_{31}$ are relevant to the analysis, while the remaining values are almost zero. In this figure, $L_{11}$ takes positive values, while $L_{33}$ has negative values. It is also observed that the only nonzero shear strain rates are the two components $L_{31}$ and $L_{13}$, which are associated with the $\mathrm{RD}(1) / \mathrm{ND}(3)$ plane. The component $L_{31}$ is essentially induced by shape changes of element in the roll-gap, while the component $L_{13}$ mainly results from the friction between roll and sheet surface. These observations are consistent with those made in a number of literature works (see, e.g., [47-51]).

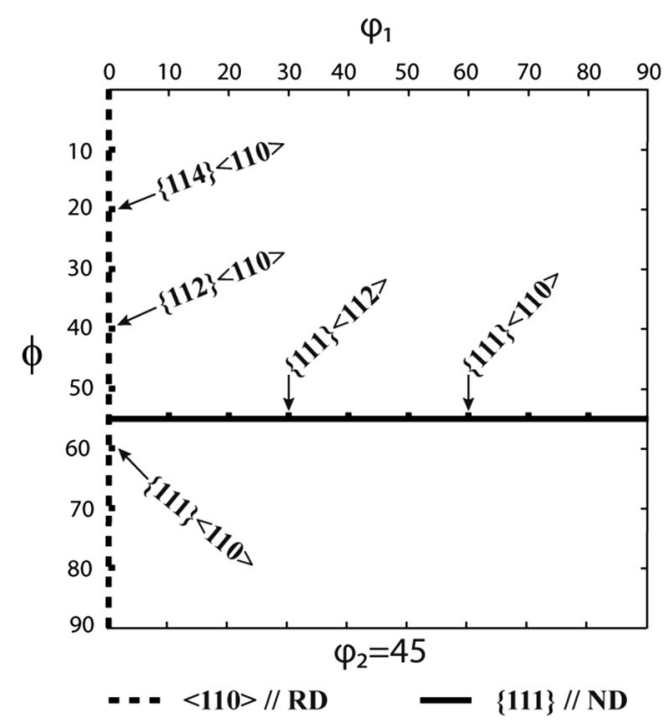

Fig. 11 Some orientations in $\operatorname{ODF} \varphi_{2}=45^{\circ}$ section 
Fig. 12 Evolution of orientation distribution functions, in midthickness of the sheet metal, for some selected orientations of the alpha fiber according to the reduction: (a) real material; (b) pseudo-material with 5000 grains

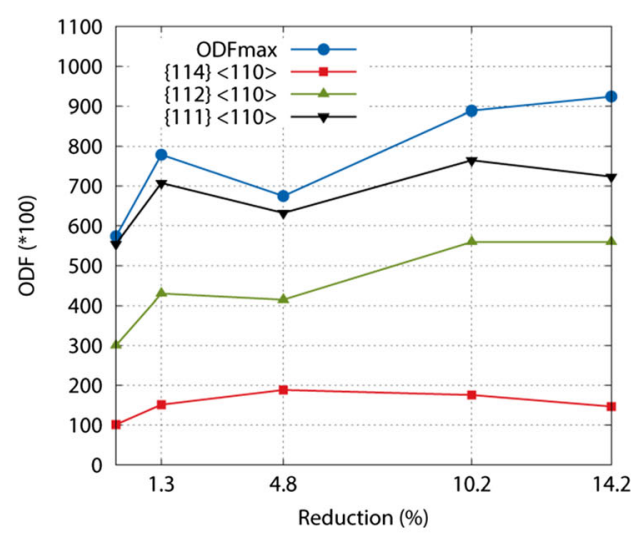

(a)

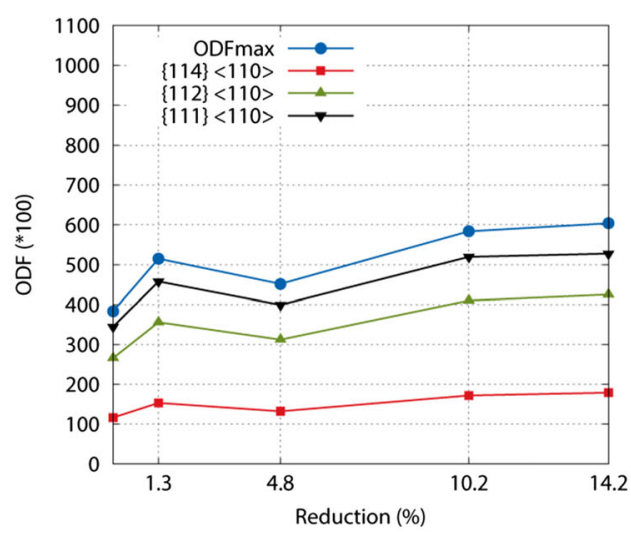

(b)
The analysis of strain evolution is based on the GreenLagrange strain tensor, within the large strain framework. The expression of this Lagrangian strain tensor is given by the following equation:

$\mathbf{E}=\frac{1}{2}\left(\mathbf{F}^{T} \mathbf{F}-\mathbf{1}\right)$

with $\mathbf{F}$ the deformation gradient, and $\mathbf{1}$ the second-order identity tensor.

Figure 8 shows the evolution of the strain, at different reductions, along the rolling direction. Again, among the six components of the strain tensor, only three components are non-zero, namely $\mathrm{E}_{11}, \mathrm{E}_{33}$, and $\mathrm{E}_{13}$. In this figure, $E_{11}$ takes positive values, while $E_{33}$ has negative values. There is also a low shear in the 13 direction, whose magnitude increases with the increase in the percentage of reduction.

For step 2, the loading path extracted from the preliminary FE calculation will be introduced as input data for the selfconsistent polycrystalline model. Then, at different reductions, 5000 new crystallographic orientations are selected in order to represent the material texture associated with each of these reductions. These crystallographic orientations, corresponding to various reductions, will be used to compute the associated ODF for the studied material.

\section{Prediction and analysis of deformation textures in temper rolling}

For the polycrystalline model, the identified material parameters are reported in Table 2.

Numerical simulation of texture evolution during cold temper rolling is conducted here to assess the decoupling strategy proposed in this work. Textures are characterized quantitatively by means of ODFs, which are plotted in 3D Euler space $\left\{\varphi_{1}, \phi, \varphi_{2}\right\}$, following Bunge's notation (see [39, 40]). For the orthotropic symmetry of rolled sheet and cubic crystal, $\left\{\varphi_{1}, \phi, \varphi_{2}\right\}$ vary in the reduced range $0-\pi / 2$.

In Figs. 9 and 10, we compare, for different reductions, the simulated textures with experimental ones for the alpha and gamma fibers, respectively. The alpha fiber comprises orientations with $\mathrm{RD} / /<1 \quad 10>$ and the gamma fiber the $<111>$ orientations parallel to the sheet normal direction ND. We note that the maxima for alpha fibers are around $\phi=55^{\circ}$; while for gamma fibers, they are located around the $\{111\}\langle 112\rangle$ orientation. These observations
Fig. 13 Evolution of orientation distribution functions, in midthickness of the sheet metal, for some selected orientations of gamma fiber according to the reduction: (a) real material; (b) pseudo-material with 5000 grains

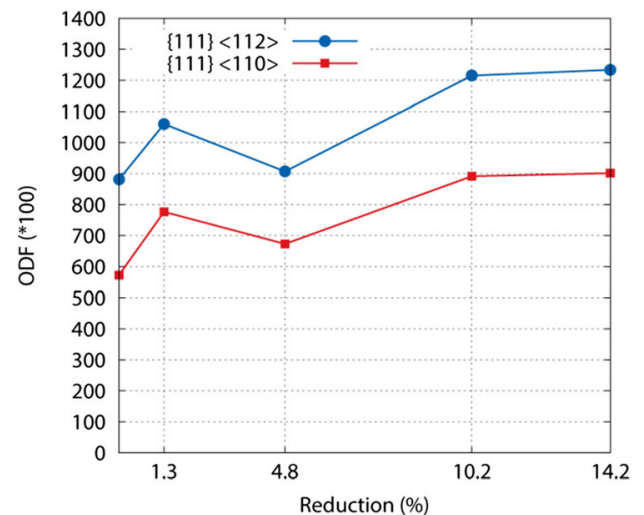

(a)

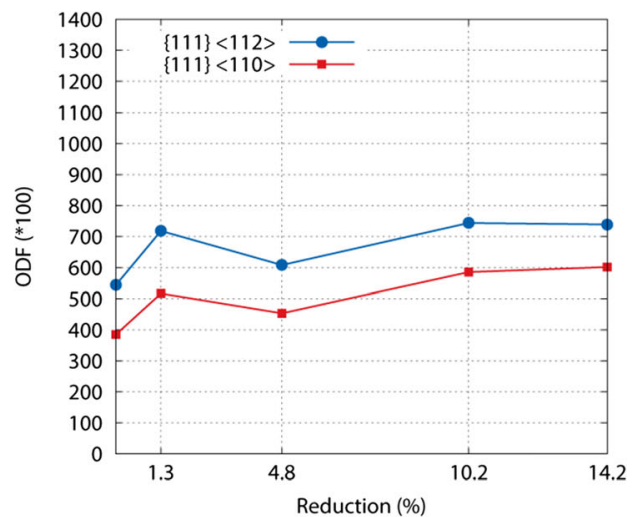

(b) 
are in agreement with the works reported in [52] and [53]. On the whole, Figs. 9 and 10 reveal that, qualitatively, the trends predicted by the simulation are in good agreement with the reported experimental measurements, although the magnitudes of the densities are lower. It should be noted that the techniques used to quantify the ODF densities from the simulations are significantly different compared to those used to quantify them from experiments. In the simulations, we start with a set of discrete grain orientations and compute ODF densities by binning them in the Euler angle space. In the measurements, however, we start with multiple measured pole figures, and numerically compute the ODFs using spherical harmonic methods. Some of the differences in magnitudes (not the trends) between the predictions and the measurements may indeed be attributable to the differences in procedures for estimating the ODF densities. These observations regarding the qualitative nature of the agreement as well as the associated interpretation for the potential sources of the differences are consistent with those made by Bachu and Kalidindi [54].

We are also interested in the orientations most present in the material. In Figs. 12 and 13, respectively, we plot the ODF evolution for orientations $\{114\}\langle 110\rangle,\{112\}\langle 110\rangle$, $\{111\}\langle 110\rangle$ of the alpha fiber, and orientations $\{111\}\langle 112\rangle$, $\{111\}\langle 110\rangle$ of the gamma fiber (see also the additional description in Fig. 11 for further details). We note an increase in the ODF intensity between the initial texture and the texture of the material at $1.3 \%$ of reduction, followed by a decrease in the intensity at $4.8 \%$ of reduction. Then, the ODF intensity increases again continuously for the other reductions. These trends obtained by numerical simulation are similar to those revealed by the experimental results, although the intensity of the respective ODFs is different.

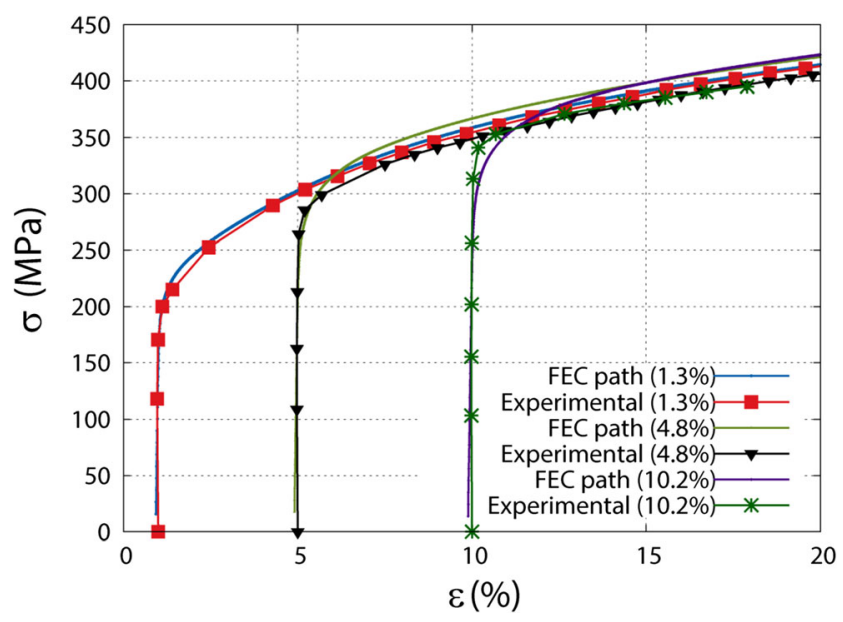

Fig. 14 Comparison between simulation and experimental results for the stress-strain curves corresponding to uniaxial tensile tests, after temperrolling prestrain at three different reductions, performed along the rolling direction $\left(\alpha=0^{\circ}\right)$

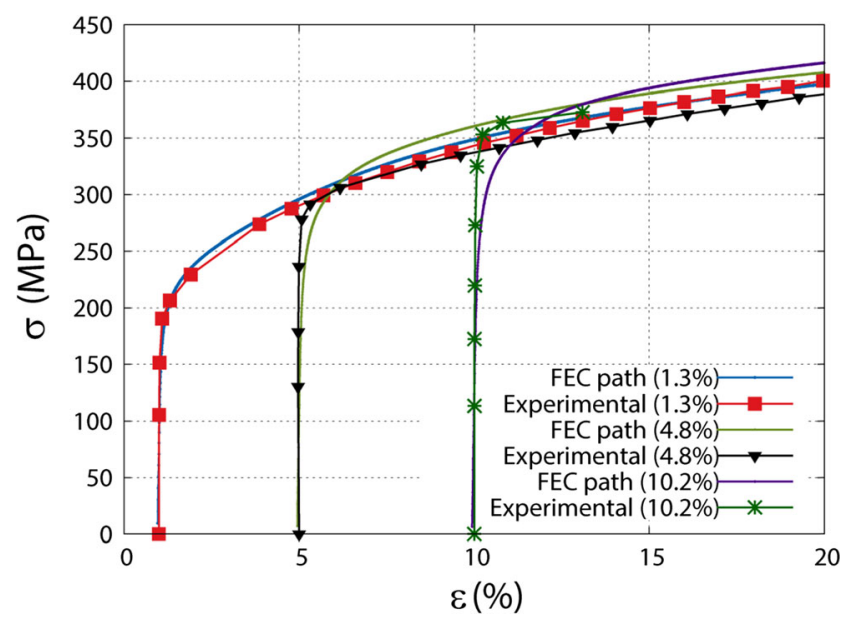

Fig. 15 Comparison between simulation and experimental results for the stress-strain curves corresponding to uniaxial tensile tests, after temperrolling prestrain at three different reductions, performed at $\alpha=45^{\circ}$ with respect to the rolling direction

\section{Prediction and analysis of the mechanical behavior of a material after temper-rolling prestrain}

In this section, we investigate the macroscopic behavior of a material prestrained through temper rolling. After different amounts of prestrain, corresponding to temper rolling at different reductions, monotonic uniaxial tensile tests are performed along the three directions $\left(\alpha=0^{\circ}, \alpha=45^{\circ}, \alpha=90^{\circ}\right)$, with respect to the rolling direction (RD) (see Fig. 17).

Figures 14, 15, and 16 show comparisons between the experimental results and those yielded by the self-consistent polycrystalline model. In these figures, the stress-strain curves represent the uniaxial tensile responses after temperrolling prestrain at three reductions ranging between 1.3 and $10.2 \%$. The curves clearly show the effect of temper rolling on the hardening behavior of the IF steel during uniaxial

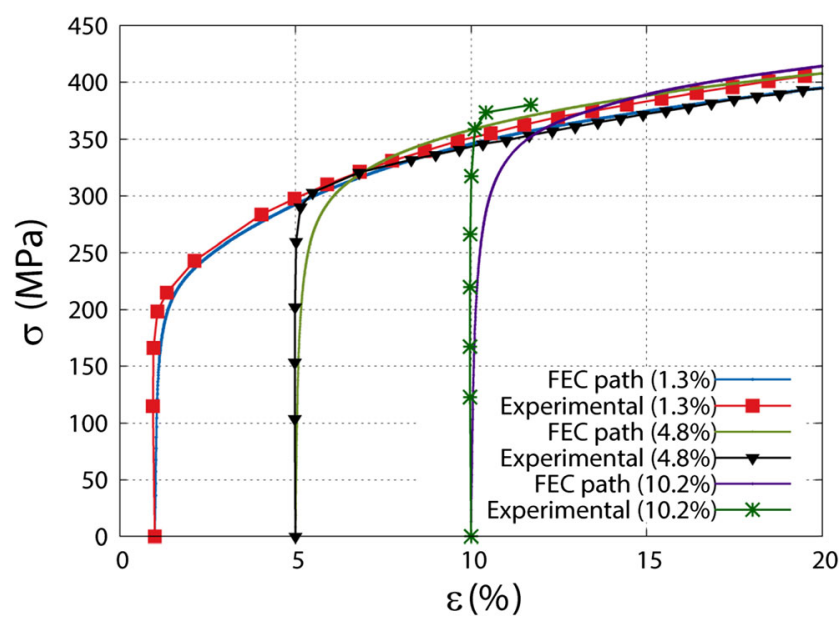

Fig. 16 Comparison between simulation and experimental results for the stress-strain curves corresponding to uniaxial tensile tests, after temperrolling prestrain at three different reductions, performed along the transverse direction $\left(\alpha=90^{\circ}\right)$ 


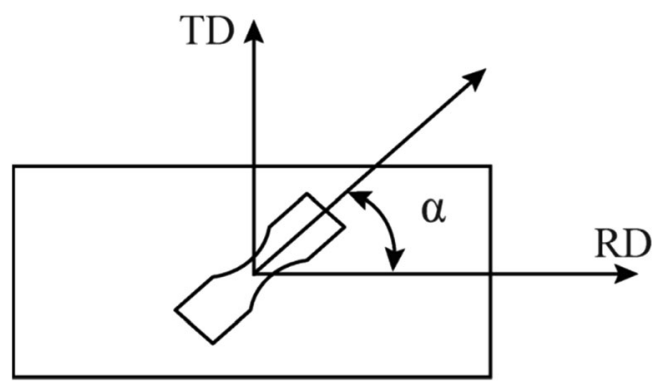

Fig. 17 Representation of the orientation of a specimen relative to the rolling direction

tensile tests. In particular, one can observe an increase of the yield stress with reduction.

From the curves reported in Figs. 14, 15, and 16, it can be noted some differences between the self-consistent simulations and the experimental results in the prediction of the material response after temper-rolling prestrain corresponding to $1.3,4.8$, and $10.2 \%$ of reduction. After $10.2 \%$ of prestrain through temper rolling, one can observe the occurrence of premature failure during the subsequent tensile strain path. This failure is due to material softening, which induces zones of highly localized deformation. Also, on the experimental curves, an increase is observed in hardening stagnation, while the model cannot accurately reproduce the observed hardening stagnation plateau.

The above-described phenomena, which are typically observed in experiments for sequential two-stage strain paths [38], are due to the spatial rearrangement of dislocation cells that takes place during loading, resulting in a specific intragranular microstructure formed during the first loading path. During the second strain path, the first structure of dislocation cells is disintegrated and another one depending on the second loading path is created, which explains the observed transient effects (e.g., plateau of hardening stagnation). Note that the hardening model that we have used does not take intragranular heterogeneity into account. To properly represent the above-discussed transient phenomena, intragranular heterogeneity should be considered within the constitutive modeling (see, e.g., Franz et al. [55, 56], Kanjarla et al. [57], Peeters [58], Peeters et al. [59, 60], Teodosiu and $\mathrm{Hu}$ [61], Hiwatashi et al. [62]).

\section{Conclusions}

In this work, we developed a weak coupling strategy, in which a polycrystalline self-consistent model, based on homogenization of elasto-plastic behavior of single crystals, is combined with the FE computer code LAM3. The main phases of this weak coupling approach consist in: (i) performing a preliminary FE calculation using a classical macroscopic model, then (ii) isolating some appropriately selected material points, which are deemed of particular interest for a deeper analysis or which seem to be critical in terms of maximum stress or strain reached, and finally (iii) exploiting the history of deformation obtained from the first calculation as input data for the polycrystalline model. This weak coupling methodology, which may also be referred to as a decoupling approach, has a number of benefits. First of all, this strategy uncouples the FE method from the polycrystalline model, thus reducing the number of variables involved in the calculation, which leads to a significant decrease in terms of computation times. We applied this technique to the temper-rolling process in order to assess the model capabilities in predicting texture evolution of a material during rolling as well as the macroscopic behavior of a material after temper-rolling prestrain followed by uniaxial tension. For validation purposes, our simulation results were compared to experimental results obtained for IF steel. Comparisons between simulation results and experiments, in terms of orientation distribution functions (ODFs) at different reductions or in terms of mechanical behavior after temper-rolling prestrain, allowed us to emphasize the predictive capabilities as well as the limitations of the proposed strategy. In particular, it is shown that the proposed approach can be used for qualitatively predicting the evolution of crystallographic texture during temper rolling. For further analysis and validation, future works will include the full implementation of the polycrystalline plasticity model into the FE code, with a hardening model that takes intragranular heterogeneity into account.

Acknowledgments This work was supported by the French program "Investment in the future" operated by the National Research Agency (ANR)-11-LABX-0008-01, LabEx DAMAS (LST). The authors are also grateful to ArcelorMittal Research Division for having provided the experimental data.

\section{References}

1. Poortmans S, Duchêne L, Habraken AM, Verlinden B (2009) Modelling compression tests on aluminium produced by equal channel angular extrusion. Acta Mater 57:1821-1830

2. Gawad J, Van Bael A, Eyckens P, Samaey G, Van Houtte P, Roose D (2013) Hierarchical multi-scale modeling of texture induced plastic anisotropy in sheet forming. Comput Mater Sci 66:65-83

3. Van Houtte P, Gawad J, Eyckens P, Van Bael P, Samaey G, Roose D (2012) Multi-scale modelling of the development of heterogeneous distributions of stress, strain, deformation texture and anisotropy in sheet metal forming. Procedia IUTAM 3:67-75

4. Van Houtte P, Kanjarla AK, Van Bael A, Seefeldt M, Delannay L (2006) Multiscale modelling of the plastic anisotropy and deformation texture of polycrystalline materials. Eur J Mech - A/Solids 25: 634-648

5. Tóth LS, Molinari A (1994) Tuning a self consistent viscoplastic model by finite element results-II. Application to torsion textures. Acta Metall Mater 42:2459-2466

6. Peirce D, Asaro RJ, Needleman A (1982) An analysis of nonuniform and localized deformation. Acta Metall 30:1087-1119 
7. Roters F, Eisenlohr P, Hantcherli L, Tjahjanto DD, Bieler TR, Raabe D (2010) Overview of constitutive laws, kinematics, homogenization and multiscale methods in crystal plasticity finite-element modeling : Theory, experiments, applications. Acta Mater 58:11521211

8. Boudifa M, Saanouni K, Chaboche J (2009) A micromechanical model for inelastic ductile damage prediction in polycrystalline metals for metal forming. Int J Mech Sci 51:453-464

9. Zamiri AR, Pourboghrat F (2010) A novel yield function for single crystals based on combined constraints optimization. Int J Plast 26: 731-746

10. Zamiri A, Pourboghrat F (2007) An effective computational algorithm for rate-independent crystal plasticity based on a single crystal yield surface with an application to tube hydroforming. Int J Plast 23:1126-1147

11. Zhang H, Dong X, Wang Q, Zeng Z (2012) An effective semiimplicit integration scheme for rate dependent crystal plasticity using explicit finite element codes. Comput Mater Sci 54:208-218

12. Li HW, Yang H, Sun ZC (2008) A robust integration algorithm for implementing rate dependent crystal plasticity into explicit finite element method. Int J Plast 24:267-288

13. Li DY, Peng YH, Zhang SR, Liu SR (2009) Numerical simulation of sheet metal stamping by using ODF data. Int J Mech Sci 51:4151

14. Guan Y, Pourboghrat F (2006) Finite element modeling of tube hydroforming of polycrystalline aluminum alloy extrusions. Int $\mathrm{J}$ Plast 22:2366-2393

15. Segurado J, Lebensohn RA, Llorca J, Tomé CN (2012) Multiscale modeling of plasticity based on embedding the viscoplastic selfconsistent formulation in implicit finite elements. Int J Plast 28: 124-140

16. Mathur KK, Dawson PR (1989) On modeling the development of crystallographic texture in bulk forming processes. Int J Plast 5:6794

17. Habraken AM, Duchêne L (2004) Anisotropic elasto-plastic finite element analysis using a stress-strain interpolation method based on a polycrystalline model. Int J Plast 20:1525-1560

18. Peirce D, Asaro RJ, Needleman A, Park A (1983) Material rate dependence and localized deformation in crystalline solids. Acta Metall 31:1951-1976

19. Asaro RJ, Needleman A (1984) Texture development and strain hardening in rate dependent polycrystals. Acta Metall 33:923-953

20. Kalidindi SR, Anand L (1992) An approximate procedure for predicting the evolution of crystallographic texture in bulk deformation processing of fcc metals. Int J Mech Sci 34:309-329

21. Jung K-H, Kim D-K, Im Y-T, Lee Y-S (2013) Prediction of the effects of hardening and texture heterogeneities by finite element analysis based on the Taylor model. Int J Plast 42:120-140

22. Franciosi P, Zaoui A (1991) Crystal hardening and the issue of uniqueness. Int J Plast 7:295-311

23. Anand L, Kothari M (1996) A computational procedure for rateindependent crystal plasticity. J Mech Phys Solids 44:525-558

24. Busso EP, Cailletaud G (2005) On the selection of active slip systems in crystal plasticity. Int J Plast 21:2212-2231

25. Arul Kumar M, Mahesh S (2012) Banding in single crystals during plastic deformation. Int J Plast 36:15-33

26. Marin EB, Dawson PR (1998) Elastoplastic finite element analyses of metal deformations using polycrystal constitutive models. Comput Methods Appl Mech Eng 165:23-41

27. Jafarlou D, Hassan M, Mardi NA, Zalnezhad E (2014) Influence of Temper Rolling on Tensile Property of Low Carbon Steel Sheets by Application of Hill 48 Anisotropic Yield Criterion. Procedia Eng $81: 1222-1227$

28. Yoshida F, Kaneda Y, Yamamoto S (2008) A plasticity model describing yield-point phenomena of steels and its application to FE simulation of temper rolling. Int J Plast 24:1792-1818
29. Roberts WL (1983) Cold Rolling of Steels. Marcel Dekker, New York

30. Lipinski P, Berveiller M (1989) Elastoplasticity of microinhomogeneous metals at large strains. Int J Plast 5:149-172

31. Franz G, Abed-Meraim F, Lorrain J-P, Ben Zineb T, Lemoine X, Berveiller M (2009) Ellipticity loss analysis for tangent moduli deduced from a large strain elastic-plastic self-consistent model. Int J Plast 25:205-238

32. Franz G, Abed-meraim F, Berveiller M (2013) Strain localization analysis for single crystals and polycrystals : Towards microstructure-ductility linkage. Int J Plast 48:1-33

33. Iwakuma T, Nemat-Nasser S (1984) Finite elastic-plastic deformation of polycristalline metals. Proc R Soc L A 394:87-119

34. Lipinski P, Berveiller M, Reubrez E, Morreale J (1995) Transition theories of elastic-plastic deformation of metallic polycrystals. Arch Appl Mech 65:291-311

35. Berveiller M, Fassi-Fehri O, Hihi A (1987) The problem of two plastic and heterogeneous inclusions in an anisotropic medium. Int J Eng Sci 25:691-709

36. Eshelby J (1957) The determination of the elastic field of an ellipsoidal inclusion and related problems. Proc R Soc L A 241:376396

37. Hill R (1965) Continuum micro-mechanics of elastoplastic polycrystals. J Mech Phys Solids 13:89-101

38. Nesterova E, Bacroix B, Teodosiu C (2001) Experimental observation of microstructure evolution under strain-path changes in lowcarbon IF steel. Mater Sci Eng A 309-310:495-499

39. Bunge H (1969) Mathematische Methoden der Texturanalyse. Akademie-Verlag, Berlin

40. Bunge H (1982) Texture Analysis in Materials Science. Butterwort, London

41. François M, Sprauel J, Lebrun J (1991) Construction of a pseudomaterial representation of a real textured material from ODF or direct pole figures. Textures Microstruct 14-18:169-174

42. Bachmann F, Hielscher R, Schaeben H (2010) Texture Analysis with MTEX - Free and Open Source Software Toolbox. Solid State Phenom 160:63-68

43. Hacquin A, Montmitonnet P, Guillerault J-P (1996) A steady state thermo-elastoviscoplastic finite element model of rolling with coupled thermo-elastic roll deformation. J Mater Process Technol 60:109-116

44. Abdelkhalek S, Montmitonnet P, Legrand N, Buessler P (2008) Manifested flatness predictions in thin strip cold rolling. Int $\mathrm{J}$ Mater Form 1:339-342

45. Abdelkhalek S, Zahrouni H, Potier-Ferry M, Legrand N, Montmitonnet P, Buessler P (2009) Coupled and uncoupled approaches for thin cold rolled strip buckling prediction. Int $\mathrm{J}$ Mater Form 2:833-836

46. Nakhoul R, Montmitonnet P, Legrand N (2014) Manifested flatness defect prediction in cold rolling of thin strips. Int J Mater Form 8: 283-292

47. Kang HG, Kim JK, Huh MY, Engler O (2007) A combined texture and FEM study of strain states during roll-cladding of five-ply stainless steel/aluminum composites. Mater Sci Eng A 452-453: 347-358

48. Kim E-Y, Cho J, Kim H-W, Choi S-H (2011) Evolution of deformation texture in $\mathrm{Al} / \mathrm{Al}-\mathrm{Mg} / \mathrm{Al}$ composite sheets during cold-roll cladding. Mater Sci Eng A 530:244-252

49. Decroos K, Sidor J, Seefeldt M (2013) A New Analytical Approach for the Velocity Field in Rolling Processes and Its Application in Through-Thickness Texture Prediction. Metall Mater Trans A 45: 948-961

50. Engler O, Huh MY, Tome CN (2000) A Study of ThroughThickness Texture Gradients in Rolled. Metall Mater Trans A 31: 2299-2315 
51. Lee CS, Duggan BJ (1991) A simple theory for the development of inhomogeneous rolling textures. Metall Trans A 22:2637-2643

52. Nicaise N, Berbenni S, Wagner F, Berveiller M, Lemoine X (2011) Coupled effects of grain size distributions and crystallographic textures on the plastic behaviour of IF steels. Int J Plast 27:232-249

53. Van Houtte P, Li S, Seefeldt M, Delannay L (2005) Deformation texture prediction: from the Taylor model to the advanced Lamel model. Int J Plast 21:589-624

54. Bachu V, Kalidindi SR (1988) On the accuracy of the predictions of texture evolution by the finite element technique for $\mathrm{fcc}$ polycristals. Mater Sci Eng A 257:108-117

55. Franz G, Abed-Meraim F, Ben Zineb T, Lemoine X, Berveiller M (2009) Role of intragranular microstructure development in the macroscopic behavior of multiphase steels in the context of changing strain paths. Mater Sci Eng A 517:300-311

56. Franz G, Abed-Meraim F, Ben Zineb T, Lemoine X, Berveiller M (2011) Impact of intragranular microstructure development on ductility limits of multiphase steels. Mater Sci Eng A 528:3777-3785

57. Kanjarla AK, Van Houtte P, Delannay L (2010) Assessment of plastic heterogeneity in grain interaction models using crystal plasticity finite element method. Int J Plast 26:1220-1233
58. Peeters B (2002) Multiscale modelling of the induced plastic anisotropy in IF steel during sheet metal forming. Katholieke Universiteit Leuven

59. Peeters B, Seefeldt M, Teodosiu C, Kalidindi SR, Van Houtte P, Aernoudt E (2001) Work-hardening/softening behaviour of b.c.c. polycrystals during changing strain paths: I. An integrated model based on substructure and texture evolution, and its prediction of the stress-strain behaviour of an IF steel during two-stage strain paths. Acta Mater 49:1607-1619

60. Peeters B, Bacroix B, Teodosiu C, Van Houtte P, Aernoudt E (2001) Work-hardening/softening behaviour of b.c.c. polycrystals during changing strain: II. TEM observations of dislocation sheets in an IF steel during two-stage strain paths and their representation in terms of dislocation densitiesActa Mater 49:1621-1632

61. Teodosiu C, Hu Z (1995) Evolution of the intragranular microstructure at moderate and large strains. In: Shen SF, Dawson PR (eds.) Proc. of Numiform'95, Simulation of Materials Processing: Theory, Methods and Applications, Balkema, Rotterdam, pp 173-182

62. Hiwatashi S, Van Bael A, Van Houtte P, Teodosiu C (1997) Modelling of plastic anisotropy based on texture and dislocation structure. Comput Mater Sci 9:274-284 